\title{
Can Globish be the Language of the World? Examining the Effectiveness of Using Highly Simplified English in International Education
}

\author{
Kristine Newton \\ Kent State University
}

\begin{abstract}
Globish has exploded to become a - language of the world. This paper will examine both the benefits, and limitations, of non-native English speakers utilizing Globish to communicate with other nonnative speakers, as well as with native English speakers. It will also examine whether students who utilize - Globish as their tool for English communication with others are adequately prepared to be actively engaged with other cultures and be effective contributors in the interconnected global market.
\end{abstract}

\section{Introduction}

These guidelines include complete descriptions of the fonts, spacing, and related information for producing your proceedings manuscripts. Please follow them.

\section{Formatting your paper}

"I'm crazy about English, says my friend Jim. Jim is from Hubei province in China and has never stepped on American soil; yet he possesses a prevailing passion for English. Around the world, there is an eagerness to speak English. Simon Kuper states that currently approximately one in four humans speaks at least some English, and many more want to learn it [1]. English is used as an official language in over 90 countries [2]. Experts assert that now there are more non-native English speakers than native English speakers: "The largest English-speaking nation in the world, the United States, has only about 20 percent of the world's English speakers. In Asia alone, an estimated 350 million people speak English, about the same as the combined English-speaking populations of Britain, the United States and Canada" [3]. But why is English so popular? Some experts argue that the practical and flexible properties of the English language (e.g. its flexible grammar and lack of masculine and feminine forms) make it both easy to learn and to export to other parts of the world [4]. Currently, English dominates the academic world. Many top tier academic research journals are printed and read in English. Also, fluency in English often provides individuals the opportunities for career mobility and overseas study [5]. However, the English language is evolving.
Previously, English was usually perceived in two forms: British and American. However, in actuality, English is extremely diverse, and varies in dialects and vernaculars, depending on the region. Some linguists say that as English continues to spread, it will fragment, as Latin did, into a family of dialectsperhaps eventually fully fledged languages - known as Englishes [3]. Keith Davidson lists the main varieties of regional English: British and Irish, American and Canadian, Australian and New Zealand, African, Caribbean, South Asian, East Asian [6]. The primary purpose of speaking has also changed. Before, students studied English to be able to communicate with native English speakers; now they study English as a lingua franca to communicate with speakers of other languages [7]. In other words, Koreans will use English to speak to Indians; Cubans will communicate in English with Israelis. Joachim Grzega states that for many beginning English learners, the goal is not to learn the culture of native English-speaking countries, but rather to simply be able to communicate competently with - foreigners. He says, "They see English as a tool for exchanging information and ideas and for creating social bonds..." [8]. All these non-native speakers will use English to effectively communicate with each other.

Several preconceptions regarding English have caused communication difficulties, especially for non-native English speakers, when attempting to navigate in the international English world. Many non-native English speakers struggle with the idioms, jokes, and nuances of English. Kuper asserts, "They are confused by idioms, half-sentences, references to ancient TV programmes, or simply the British [and American] habit of not saying what you mean" [1]. Native English speakers, also known as Anglophones, expect the non-native speakers to understand everything that is spoken [9]. Anglophones tend to dominate the discourse, making no concessions in their speech, causing those confused by the Anglophones' idioms to sit in uncomfortable silence [6]. "These foreign audiences were terrified to ask for clarification and generally were lulled into boredom, especially if the accent was difficult and the diction too fast" [10]. Finally, there is a preconception that to communicate effectively in English, one must adopt the accent of a native English speaker. Therefore, many nativeEnglish speakers (especially Americans) tend to have a low tolerance for accented English.

Currently, many non-native speakers have begun using an incredibly reduced version of English, 
called Globish, to communicate with others (especially in international business world). Globish is an extremely simplified form of English which dispenses the complexities of grammar, yet is still comprehensible to non-native English speakers and Anglophones. Globish consists of a limited vocabulary of 1,500 words which can be awkwardly assembled to express more complicated thoughts, and allows non-native English speakers to state the same thing is different ways to make up for difficulties in pronunciation [9]. Codified by retired vice president of I.B.M. Jean-Paul Nerriere in 2004, Globish utilizes simple sentence structure, no jokes, and no unintelligible idioms. Nerriere's web site, Globish.com, boasts that Globish allows non-native English speakers to do the following:

- Communicate in English, using only 1500 words.

- Employ simple, but standard grammatical structure.

- Learn enough pronunciation and spelling for 1500 words only.

- Provide a tool for leading a conversation in business or as a tourist, anywhere in the world [11].

\section{Theoretical Framework}

The purpose of this paper was to discover if students who utilize "Globish" as their tool for English communication with others are adequately prepared to be actively engaged with other cultures and be effective contributors in the interconnected global market. A functionalist theoretical approach was used to examine both the benefits, and limitations, of utilizing Globish to communicate in the international world.

\section{Is Globish Effective?}

Communication experts like Jessica Lichy assert that "English will probably remain the universal language of global communication..." She also states that non-native speakers may not have same knowledge or proficiency level of the language, but still need to communicate, especially in the realm of international business, since for many businesses worldwide, English is the primary language of international communication [12]. In short, English is prevalent in the international business community and is spoken, online and offline, in workplaces around the world. Globish provides that bridge to communicate important information. It also takes less time to learn than Standard English. Rather than studying English for years, students can take less time to learn Globish, and possess enough English language proficiency to "get by" and communicate necessary information to Anglophones as well as other non-native speakers. Some scholars have even suggested that native speakers learn Globish in order to communicate more effectively. Mydans states, "A native speaker might need to become bilingual in his own language to converse with other speakers of Global English" [3]. Native speakers may need to learn Globish, especially if they expect to interact heavily in the international business community. Robert Badal purports that the major facets of the modern world, such as the global economy as well as the Internet, have has forever intertwined education and economics, and pushed non-native speakers to seek help with their workplace English issues [13]. There is a large desire to learn English, and to learn it quickly.

However, Globish does have its risks and limitations. For instance, Anglophones can find Globish tedious to listen to and to speak [9]. Without idioms, nuances and jokes, English becomes less conversational and tends to sound more robotic. Some experts even assert that native English speakers will not be able to understand Globish [13]. Also, Globish does not establish language proficiency enough to "penetrate foreign societies" [1]. Globish, instead, is more topical, allowing enough language proficiency for minimal survival in a foreign community. The limitations of Globish become painfully apparent when non-native speakers face situations that require a level of English higher than just communicating information. Robert Badal details the problems one of his Business English students in Japan faced:

In Japan, one of my first private adult students had a reconditioned used forklift business that did business in China, Russian, and India, among others - all in English. His problem was not business terms, it was in the networking/bonding part of business - which is the time spent drinking and eating together - and speaking casual English. [13]

Building connections is crucial in any international dealings, whether it is education, commerce or law. In a global society, these connections develop into communities and cultures. Globish helps build this connection, but the connection is limited.

Some experts even fear that many Anglophones will have an even less desire to learn a foreign language. Kuper states, "Why spend years learning to order a beer in bad French, when you can order it in Globish?" [1]. Finally, in a failed attempt to communicate in Globish, there is the risk of Anglophones accommodating their speech to the point of risking miscommunication and even offending the non-native English speaker. Liana Bairros de Souza warns that "the speaker may adjust his/her 
speech more than necessary, which is known as the phenomenon of 'overaccommodation'. It often causes miscommunication, although the intention was the opposite" [7]. Globish can be beneficial, but it must be used with caution.

\section{Teachers}

Teaching English is a multi-billion dollar industry; experts estimate that approximately one-third of the world will soon be learning English [3]. Countries across the globe recognize English as a global tool and are introducing English instruction early in schools [9]. Countries like China are introducing English to their students as early as kindergarten and the first grade. Whereas in the United States, many schools still do not start teaching foreign languages until the sixth or seventh grade, sometimes not until high school.

There are pedagogical prejudices facing the English as a Second Language (ESL) classroom. Students taking English classes, as with many foreign language students, expect one specific standard pronunciation. Liana Bairros de Souza says that "they still have this preconception that a standard monolithic accent is what they need to communicate with other foreigners, disregarding the vast range of foreign people who speak English with different accents" [7]. Many non-native English speaking teachers also struggle with their own prejudices in the classroom. Some teachers believe they are not prepared to teach pronunciation since they themselves cannot speak proper English (i.e. as a native speaker). Bairros de Souza contends that this ill prepares these students for the international world: EFL students are not being prepared to face the different varieties of English since they are not shown these by their teachers. This can cause problems because students who are not aware of accent variations may think the English they were presented to is the only one and may feel misplaced or uncomfortable, or even frustrated and disappointed when facing a different environment [7]. English pronunciation is important between Anglophones and non-native speakers, but not as important between non-native speakers [7]. Thus the goal of learning English pronunciation should be to be understood, instead of trying to sound like a native speaker. After all, English does not have to be perfect to be understood. Finally, another misconception facing the ESL/EFL classroom is the myth that English is best taught by native speakers. Bairros de Souza contradicts this point when she quotes language specialist Jennifer Jenkins who indicates that non-native speaking teachers actually posses the advantage in schools:

'NS' [Native Speaking] teachers are, by and large, equipped with knowledge only in a 'privileged' intuitive sense, and with pedagogic competence only to a 'rudimentary' degree. By contrast, 'NNS' [Non Native Speaking] teachers know the 'subject' English, in an explicit rather than intuitive sense, by virtue of having themselves learnt it as a 'foreign' language and as a result of this, their pedagogic 'credentials' are more 'credible.' [7]

Globish provides a bridge to communicate information, but Globish has severe limitations. Unlike Standard English, Globish is less conversational and tends to sound robotic. Also, Globish allows only minimal language proficiency for survival in a foreign community. There is also the risk of Anglophones accommodating their speech to the point of risking miscommunication and even offending non-native English speakers. Finally, negative pedagogical attitudes in the English as a Second Language (ESL) classroom are hindering building international intelligibility. Eliminating these prejudices will increase students' exposure to the varieties of English and better prepare them to be successful in the global market.

\section{Communication Adjustment Theory (CAT)}

One must not master all aspects in English to be able to sufficiently communicate in English. Bairros de Souza validates the use of Globish when she states, "one cannot be the correct English since it is no longer used by its native speakers in order to show their identity but a way to communicate among foreigners who speak different languages themselves. Without boundaries or determined culture, English is used as a lingua franca where communication is the main goal" [7]. But can speaking Globish build global competency? The answer is no. The most effective type of international communication requires global competency. Globish does not build global competency and ill equips speakers/students for cultural differences, such as differences in body language, gestures, and personal space. For instance, Grzega discusses the challenge of politeness during intercultural communication. According to the author, the level of politeness varies among cultures; over-politeness can be irritating and under-politeness is considered rude [8]. Globish does not address these types of cultural issues. Simply put, Globish is not enough.

Robert McCrum, author of Globish: how the English language became the world's language, insists that "in the short term, Globish is set to only grow" [14]. Some critics fear that Globish will become the new English. Globish is not a one size fits all English; and it has severe limitations. Lichy 
advises that "neither globish nor offshore English can equip the speaker for the pitfalls that can arise from cultural differences or the varying meanings and use of body language in different cultures" [12]. This lack of global competency will prevent Globish from dominating the language world. Kuper asserts that in conversations with native English speakers, the native speakers maintain the advantage of steering the conversation. They have the ability to 'drop into Globish' when required, and when clarification or speed is required, will often steer the conversation by using phrases like "So what you're saying is" [1]. Although Globish is a sufficient starting point, experts concur that most English learners will not stop at the Globish level. However, experts also state that the greatest disadvantage is only speaking one language. "It is after all the monolingual 'native' speaker of a single variety of a standard global language who is the most linguistically disadvantaged of all - socially, culturally, emotionally and intellectually" [6].

Native speakers don't need to reduce their English to a Globish level; however, they do need to adjust their speech to ensure intelligibility. According to Bairros de Souza, Anglophones should be aware of differences and adjust their speech in order to be understood; as well as become more phonetically tolerant. The most effective communication happens through adjustments. Liana Bairros de Souza asserts this point in her Communication Accommodation Theory (CAT): speakers, whether native or non-native speakers, should adjust their speech in order to be understood:

Speakers need to develop the ability to adjust towards that particular interlocutor. While listeners need to develop greater tolerance of accent difference as well as to adjust their expectations according to the specific interlocutor. Listeners should not expect standard pronunciation; they must also learn to cope with a certain amount of L1 [native speakers] transfer. [7]

Applying CAT in the classroom could change the aim of English level proficiency previously held by EFL students and teachers. The goal is not to sound like a native speaker, but to be able to understand, and be understood. Teachers can uses this basis to create the context for building global competency in their students. The EFL classroom provides great opportunities to expose students to different cultures, and build global competency. "To be successful in school, English language learners must acquire both the social and the academic aspects of language as they are learning content" [15]. Globish cannot accomplish this goal. Author Claire Kramsch states, "In the foreign language class, culture is created and enacted through the dialogue between students and between teacher and students. Through this dialogue, participants not only replicate a given context of culture, but, because it takes pace in a foreign language, it also has the potential of shaping a new culture" [16]. Teachers and schools must change the aim of English level proficiency to match the goals of the students. It is not necessary for teachers to teach students to drop their accent, or to waste their time on irrelevant material. Non-native English speaking teachers need to cope with different varieties of English, and understand that they have an advantage in schools.

\section{Conclusion}

Globish provides a bridge to communicate information, but allows only minimal language proficiency and does not sufficiently address situations involving cultural differences. Secondly, negative pedagogical attitudes in the English as a Second Language (ESL) classroom are hindering building international intelligibility. Elimination of these prejudices will increase students' exposure to the varieties of English. Finally, applying CAT in the classroom could change the aim of English level proficiency previously held by EFL students and teachers, and may better prepare them to be successful in the global market.

We all need to be realistic. Language is something alive and every speaker has his/her own way to communicate and make himself or herself understood. The only stable thing about a language is that it does not stand still - it varies [7]. The English language will continue to evolve. People continue to learn it for various reasons. Globish is a practical form of communication. It works well for those who desire only minimal levels of communication. For those who desire a greater understanding, the advanced levels of Standard English will still remain.

\section{References}

[1] Kuper, S. (n.d.). Boots in the booth: Globish is Rubbish - Simon Kuper. Boots in the booth. Retrieved November 20, 2011, from http://bootsinthebooth.blogspot.com/2010/12/globis h-is-rubbish-simon-kuper.html

[2] Craig, K. (2012). No child left bewildered: Using phonetic English as a lingua franca. International Journal of Business and

Social Science, 3(8), 76-82.

[3] Mydans, Seth. "Across cultures, English is the word - The New York Times." The New York Times - Breaking News, World News \& Multimedia. N.p., n.d. Web. 7 Aug. 2012. <http://www.nytimes.com/2007/04/09/world/asia/09 iht-englede.1.5198685.html?pagewanted=all > 
[4] (2010), PROFESSIONAL NOTES. World Englishes, 29: 448-450. Issue 3

[5] Grishaeva, Y. (2008). English Is A Language Of Opportunity. Английский для человека ххі века: Владение английским языком как залог успешности на рынке труда, 12.

[6] Davidson, Keith. The nature and significance of English as a global language. English Today. Volume 23, issue 1, p. 48-50. January 2007.

[7] de Souza, L. B. (1999). Communication Accommodation Theory (CAT) and the teaching of English as a second language. Unisalle/Challenge Centro de Idiomas.

[8] Grzega, J. (2006). Globish and Basic Global English (BGE): two alternatives for a rapid acquisition of communicative

competence in a Globalized world?. Internet: Journal for EuroLinguistiX, 3, 1-13.

[9] Cohen, N. (2006, August 6). So English Is Taking Over the Globe. So What. New York Times, p. 14.

[10] Noble, E. (n.d.). ENNOBLER explains Globish. Ennoble your English, Global Communication. Retrieved November 20, 2011, from http://ennobler.net/Globish.html

[11] Globish Home - Globish.com. (n.d.). Globish Home - Globish.com. Retrieved November 19, 2011, from http://www.globish.com/

[12] Lichy, Jessica (2009) "Borders and Frontiers in the Information Age," Global Business Languages: Vol. 14, Article 2.

[13] Badal, R. (n.d.). Business English The Essential Subject. Business English. Retrieved March 19, 2013, from www.ic.nanzanu.ac.jp/tandai/kiyou/No.38/07Badal.pdf

[13] Blume, M. (2005, April 22). If you can't master English, try Globish. New York Times. Retrieved March 19, 2013, from http://www.nytimes.com/2005/04/21/arts/21ihtBlume22.html?pagewanted=all\&_r=0

[14] McCrum, R. (n.d.). All the World Speaks Globish - The Daily Beast. The Daily Beast. Retrieved November 20, 2011, from http://www.thedailybeast.com/newsweek/2010/06/1 2/glob-ish.html

[15] Gottlieb, M. H. (2006). Assessing English language learners: bridges from language proficiency to academic achievement. Thousand Oaks, Calif.: Corwin Press.

[16] Kramsch, C. J. (1993). Context and culture in language teaching. Oxford: Oxford University Press. 